\title{
Persistent sore throat and sleep apnoea: an unusual presentation of sarcoidosis
}

\author{
Nafisat Oyewale
}

Cellular Pathology, University Hospital of North Staffordshire NHS Trust, Stoke-on-Trent, UK

\section{Correspondence to} Dr Nafisat Oyewale; noyewale@doctors.org.uk

Accepted 19 December 2020

\section{DESCRIPTION}

A 30-year-old woman presented with recurrent upper respiratory tract infection, snoring and sleep difficulties diagnosed as sleep apnoea of 18 months' duration. Further history revealed that she had presented with painful nodular rashes on her legs a year prior, which was diagnosed as erythema nodosum. The rashes resolved after treatment with anti-inflammatory medication. She is otherwise fit and healthy.

Extraoral examination was unremarkable, except for bilateral diffuse neck node enlargement at level 1 and level 2, which were non-tender and diffuse, measuring $1-1.5 \mathrm{~cm}$. Intraorally, there was asymmetrical tonsil enlargement, with the left being larger. The rest of the ear, nose and throat (ENT) and general examination were normal.

Ultrasound of the neck was performed which demonstrated prominent cervical and intraparotid nodes. No sinister pathology was identified; however, in view of the worsening symptoms, the patient was consented and planned for bilateral tonsillectomy. Histology of the tonsils showed diffuse non-necrotising granulomas (figures 1 and 2). No mycobacterial or fungal organisms were found following additional stains. There was no evidence of malignancy. On diagnosis of nonnecrotising granulomatous disease, further history to exclude mycobacterial infection, such as weight loss and night sweats, was explored, of which the patient denied any. Chest radiograph was done which showed bilateral hilar lymphadenopathy (figure 3). ACE level was elevated at $104 \mathrm{U} / \mathrm{L}$ (20-70), and full blood count, liver function test, bone profile and renal function test were within normal limits. Fine needle aspiration of the cervical nodes was done to obtain materials for mycobacterial culture, which was negative.

In view of the history of erythema nodosum, bilateral hilar lymphadenopathy, elevated ACE and the

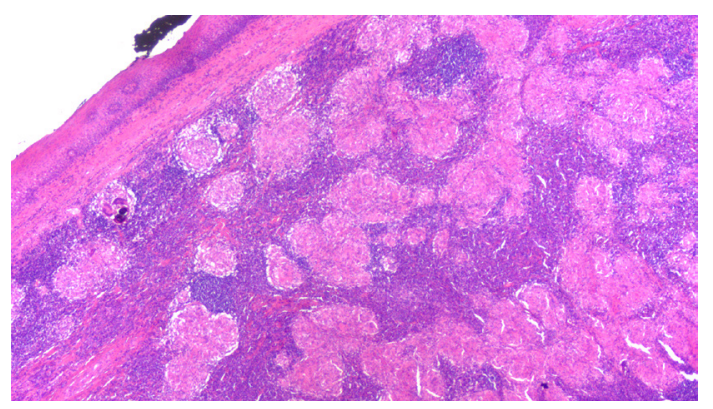

Figure $1 \quad H \& E \times 40$ illustrating diffuse non-necrotising granulomas within the tonsil.

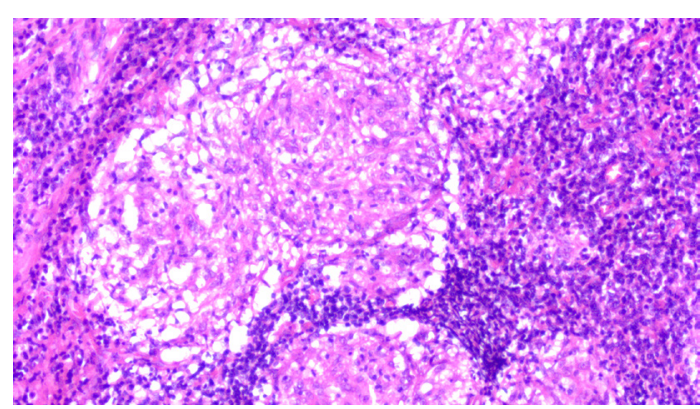

Figure $2 \quad H \& E \times 100$ illustrating diffuse non-necrotising granulomas within the tonsil.

non-necrotising nature of the tonsillar granulomas in the absence of other aetiologies, a diagnosis of sarcoidosis was made. The patient was informed of the diagnosis and has reported improved breathing after tonsillectomy. She is currently clinically stable and under follow-up by respiratory physicians.

Sarcoidosis is a systemic inflammatory disease of unknown aetiology that affects multiple organs. It is associated with non-necrotising granulomas in involved sites. In over $90 \%$ of patients, the lungs and the hilar and mediastinal lymph nodes are involved. In the literature, isolated presentation of sarcoidosis as tonsillar enlargement is rarely reported. ${ }^{12}$

Granulomatous inflammation of the tonsils is rare, and when present is usually part of presentation of systemic diseases such as sarcoidosis, Crohn's disease, fungal infection and tuberculosis. ${ }^{34}$

The diagnosis of sarcoidosis is made with the exclusion of histopathological features associated

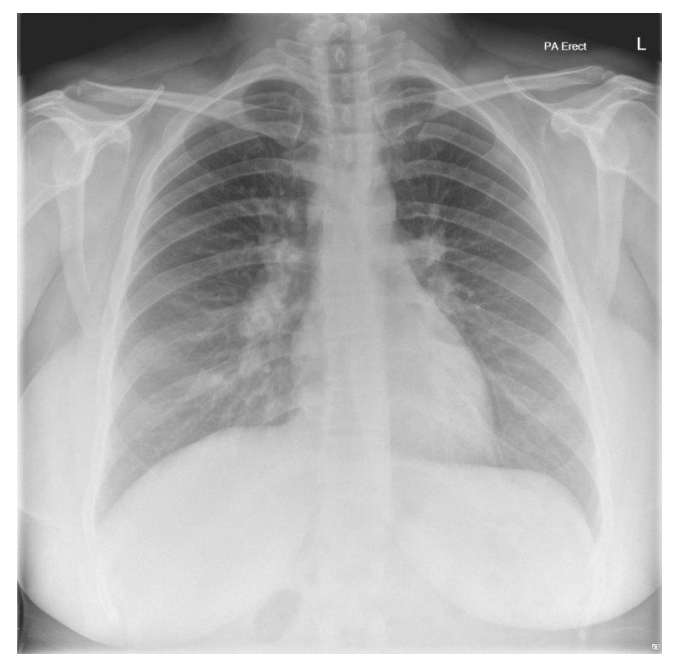

Figure 3 Chest radiograph demonstrating bilateral hilar lymphadenopathy. PA, posteroanterior. 
with other causes of granulomatous inflammation, provided compatible clinical and radiological findings are established. These include the use of Ziehl-Neelsen and silver stains to assess for mycobacterial and fungal infections, respectively.

This case highlights that sarcoidosis should be considered as a differential diagnosis in the evaluation of asymmetrical tonsil enlargement. Once sarcoidal type non-necrotising granulomatous lesions are found in tonsillar specimens, further

\section{Learning points}

Persistent sore throat and recurrent upper respiratory infection should prompt referral for thorough evaluation.

- Non-pulmonary sarcoidosis can show variable presentation and therefore sarcoidosis should be considered and excluded in the differential diagnosis of granulomatous inflammation in the tonsil.

- Sarcoidosis is a systemic disease and early diagnosis is vital for institution of management and limitation of morbidity. investigations are mandatory to confirm the diagnosis and to exclude other possible aetiologies.

Twitter Nafisat Oyewale @naffyzie

Contributors NO is the sole author responsible for conceptualisation of this paper, primary write-up, proof-reading, photography and submission of the manuscript.

Funding The authors have not declared a specific grant for this research from any funding agency in the public, commercial or not-for-profit sectors.

Competing interests None declared.

Patient consent for publication Obtained.

Provenance and peer review Not commissioned; externally peer reviewed.

\section{REFERENCES}

1 Erwin SA. Unsuspected sarcoidosis of the tonsil. Otolaryngol Head Neck Surg 1989:100:245-7.

2 Compadretti GC, Nannini R, Tasca I. Isolated tonsillar sarcoidosis manifested as asymmetric palantine tonsils. Am J Otolaryngol 2003:24:187-90.

3 Wenig BM, Devaney K, Wenig BL. Pseudoneoplastic lesions of the oropharynx and larynx simulating cancer. Pathol Annu 1995;30:143-87.

4 Kardon DE, Thompson LD, David E. A clinicopathologic series of 22 cases of tonsillar granulomas. Laryngoscope 2000;110:476-81.

Copyright 2021 BMJ Publishing Group. All rights reserved. For permission to reuse any of this content visit https://www.bmj.com/company/products-services/rights-and-licensing/permissions/

BMJ Case Report Fellows may re-use this article for personal use and teaching without any further permission.

Become a Fellow of BMJ Case Reports today and you can:

- Submit as many cases as you like

- Enjoy fast sympathetic peer review and rapid publication of accepted articles

- Access all the published articles

Re-use any of the published material for personal use and teaching without further permission

\section{Customer Service}

If you have any further queries about your subscription, please contact our customer services team on +44 (0) 2071111105 or via email at support@bmj.com.

Visit casereports.bmj.com for more articles like this and to become a Fellow 